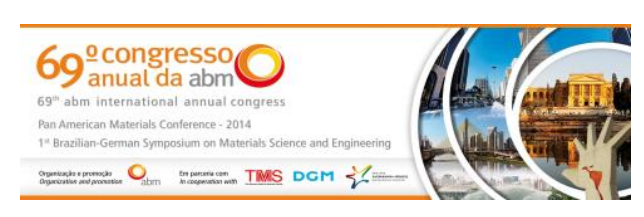

Tema: Gestão de meio ambiente e recuperação e tratamento de rejeitos

\title{
CARACTERIZAÇÃO DOS METAIS PRESENTES NA FRAÇÃO NÃO MAGNÉTICA DAS PLACAS DE CIRCUITO IMPRESSO DE COMPUTADORES*
}

\author{
Luíza Freire Arold \\ Monica Maria Correa Jiménez \\ Viviane Tavares de Moraes $^{3}$ \\ Jorge Alberto Soares Tenório ${ }^{4}$ \\ Denise Crocce Romano Espinosa ${ }^{5}$
}

Resumo

Placas de Circuito Interno (PCl's) são partes fundamentais de um computador, uma vez que são responsáveis pelo bom funcionamento deste. Porém, seu descartadas em áreas clandestinas, podem causar danos ao meio ambiente e a saúde pública, pois estas placas podem ter na sua composição elementos tóxicos que as tornam perigosas. O presente estudo visa qualificar e quantificar os metais presentes na fração não magnética das PCl's, a fim de que subsequentes processos de recuperação de metais possam ser aplicados. Para que as análises pudessem ser feitas, as PCls foram submetidas a etapas de moagem, quarteamento, separação magnética e digestão em água régia. As placas foram moídas em um moinho de martelos, utilizando grelhas de $2 \mathrm{~mm}$. O resíduo cominuído seguiu para a etapa de separação magnética, obtendo-se duas frações, uma fração magnética e uma fração não magnética. Em seguida, a fração não magnética foi quarteada em amostras de $20 \pm 5 \mathrm{~g}$. Para realizar ensaio de digestão em água régia, foi escolhida aleatoriamente uma amostra. A digestão foi realizada durante $24 \mathrm{~h}$ a temperatura ambiente usando-se uma proporção sólido: líquido de 20:1. O licor obtido nos ensaio de digestão em água régia foi levado para análise química por espectrometria de emissão óptica por indução de plasma (ICP-OES). Os resultados mostraram que as placas de circuito impresso de computadores contêm na sua fração não magnética aproximadamente $60 \%$ dos metais da placa de vídeo.

Palavras-chave: Caracterização; Placas de circuito interno; Fração não magnética.

\section{CHARACTERIZATION OF THE METALS PRESENT IN THE NON MAGNETIC FRACTION OF COMPUTERS PRINTED CIRCUIT BOARD}

\section{Abstract}

Printed Circuit Boards (PCB's) are fundamental parts of a computer, because they are responsible for its good running. Although, its disposal in clandestine areas, may cause damage to the environment and public health because these boards can be constituted by toxic elements that make them hazardous. The present study aims to qualify and quantify the metals present in the non-magnetic fraction of the PCBs, in order that following metal recovery processes can be applied. For the analyzes, the PCBs were subjected to steps of grinding, quartering, magnetic separation and digestion in aqua regia. The boards were ground in a hammer mill using $2 \mathrm{~mm}$ grid. The residue comminuted followed for the step of magnetic separation, yielding two fractions, a magnetic fraction and a non-magnetic fraction. Then, the non-magnetic fraction was divided in samples of $20 \pm 5 \mathrm{~g}$. To perform the test in aqua regia digestion, a sample was randomly chosen. Digestion was performed for $24 \mathrm{~h}$ at room temperature using a solid: liquid ratio of 20:1. The liquor obtained from the digestion trial with aqua regia was taken for chemical analysis by inductively coupled plasma optical emission spectrometry (ICP-OES). The results showed that the circuit boards of computers contains in its non-magnetic fraction approximately $60 \%$ of the metals of the video boards.

Keywords: Characterization; Printed circuit boards; Non magnetic fraction.

1 Engenharia de Materiais, Estudante, Bolsista de Iniciação Científica, Departamento de Engenharia Metalúrgica e de Materiais, Universidade de São Paulo (USP), São Paulo, SP, Brasil.

2 Eng. Química, Pesquisadora Mestrado, Depto. Eng. Metalúrgica e de Materiais, USP, São Paulo, SP, Brasil.

3 Tecnologia Ambiental, Eng. Ambiental, Doutora, Pesquisadora, Pós-Doutorado, Depto. Engenharia Metalúrgica e de Materiais, USP, São Paulo, SP, Brasil.

4 Eng. Metalúrgica, Livre Docente, Prof. Titular, Depto. Eng. Met. e Mat., USP, São Paulo, SP, Brasil.

5 Eng. Metalúrgica, Livre Docente, Prof. Associada, Depto. Eng. Met. e Mat., USP, São Paulo, SP, Brasil.

* Contribuição técnica ao 69 Congresso Anual da ABM - Internacional e ao 14ํ ENEMET - Encontro Nacional de Estudantes de Engenharia Metalúrgica, de Materiais e de Minas, 21 a 25 de julho de 2014, São Paulo, SP, Brasil. 


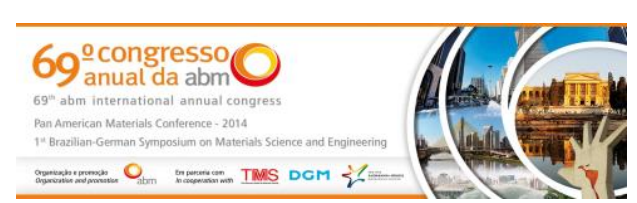

\section{INTRODUÇÃO}

A produção de equipamentos eletro eletrônicos (EEE) é um dos grandes negócios que crescem mais rapidamente no mundo atual e seu descarte, os resíduos de equipamentos eletro eletrônicos (REEE), é também considerado um dos resíduos que mais crescem no mundo [1]. A produção de equipamentos eletro eletrônicos tem crescido cada vez mais nos países em desenvolvimento. No Brasil, o setor de produção dos EEE mostrou um crescimento de $23 \%$ de 2007 a 2010 [2].

Os REEE contém componentes nocivos à saúde e ao meio ambiente como, por exemplo, cádmio e níquel, entre outros [3]. Desta maneira, é de extrema importância que os REEE sejam descartados e reciclados de maneira adequada, o que exige uma legislação específica que regule seu destino e tratamento logo após seu descarte. Na União Européia, em Agosto de 2004, uma legislação criada pelo órgão WEEE Directive foi baseada no princípio de que os produtores seriam os responsáveis pelo destino dos REEE após seu descarte [1,4]. No Japão, o órgão Designated House-Hold Appliance Recycling Law (DHARL), existente desde 2001, regula o descarte e tratamento das REEE, implementando uma grande escala baseada em um setor privado responsável pela reciclagem das REEE [1]. No Brasil, a entidade responsável por regular os resíduos eletrônicos é a Política Nacional para Resíduos Sólidos, mas, diferentemente de outros países, a política brasileira é baseada no princípio de responsabilidade divida entre produtor e consumidos [6]. Os REEE podem ser divididos entre 10 diretivas, entre elas, equipamentos de consumidores, aparelhos médicos, distribuidores automáticos e equipamentos de telecomunicação [1]. Computadores também são equipamentos eletro eletrônicos e serão tratados no presente artigo, no qual será discutida a composição da fração não magnética de placas de circuito interno de computadores, mais especificamente de placas de vídeo.

Placas de Circuito Interno (PCls) são difíceis de serem recicladas, pois possuem uma grande variedade de materiais, que são metais $(40 \%)$, polímeros $(30 \%)$ e cerâmicos (30\%) [5].

\section{MATERIAIS E MÉTODOS}

As placas de vídeo utilizadas para este estudo possuíam a composição de metais apresentada na Tabela 1. Pode-se notar que a placa contém uma fração metálica de aproximadamente $36 \%$, quantidade que condiz com o esperado pela teoria [5].

Tabela 1. Caracterização da fração metálica das placas de vídeo

\begin{tabular}{cccccccccccc}
\hline Metal & $\mathrm{Ag}$ & $\mathrm{Al}$ & $\mathrm{Au}$ & $\mathrm{Cu}$ & $\mathrm{Fe}$ & $\mathrm{Ni}$ & $\mathrm{Pb}$ & $\mathrm{Sn}$ & $\mathrm{Zn}$ & Outros & Total \\
\hline $\begin{array}{c}\text { Massa } \\
(\%)\end{array}$ & 0,1 & 1,2 & 0,03 & 23,4 & 2,2 & 1,2 & 2,1 & 2,7 & 2,2 & 0,6 & 35,8 \\
\hline
\end{tabular}

\subsection{Processo Mecânico}

Para a caracterização da fração não magnética das placas de vídeo, estas foram coletadas de computadores em desuso, doadas pelo Centro de Descarte e Reuso de Resíduos de Informática (CEDIR). As placas foram manualmente desmanteladas e posteriormente moídas em um moinho de martelos, utilizando grelhas de $2 \mathrm{~mm}$, para se obter uma boa liberação de metais. Em seguida, a placa já moída passou

\footnotetext{
* Contribuição técnica ao $69^{\circ}$ Congresso Anual da ABM - Internacional e ao 14ํㅡㄹ ENEMET - Encontro Nacional de Estudantes de Engenharia Metalúrgica, de Materiais e de Minas, 21 a 25 de julho de 2014, São Paulo, SP, Brasil.
} 


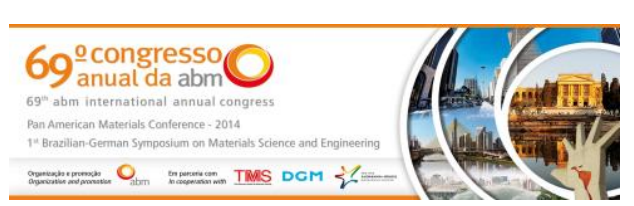

pelo processo de separação magnética, onde duas diferentes frações foram obtidas. A fração magnética foi estocada, enquanto a fração não magnética foi quarteada em amostras de $20 \pm 5 \mathrm{~g}$.

\subsection{Processo Químico}

Para a dissolução dos metais presentes na fração não magnética das placas de vídeo, foi utilizada água régia em uma proporção de 20:1 líquido/sólido. Uma amostra foi aleatoriamente escolhida, pesada, inserida na solução e deixada por 24 horas em capela, à temperatura ambiente e pressão atmosférica.

Após o repouso de 24 horas, a solução foi filtrada. Uma amostra de $45 \mathrm{~mL}$ de água régia contendo os metais dissolvidos foi recolhida, enquanto o sólido restante foi lavado, colocado em uma estufa e posteriormente pesado, a fim de se quantificar a massa total dos metais presentes na placa de vídeo por balanço de massa, considerando que o sólido restante consistia em cerâmicos e polímeros.

A amostra de $45 \mathrm{~mL}$ foi diluída com água destilada em proporções de 1:10, 1:100 e 1:1000 líquido/líquido. Em seguida, as amostras foram analisadas em espectrometria de emissão óptica por indução de plasma (ICP-OES).

\section{RESULTADOS E DISCUSSÃO}

Analisando os resultados obtidos com o ICP-OES, chegou-se à quantificação de metais apresentada pela Tabela 2.

Tabela 2. Porcentagem em massa dos metais presentes na fração não magnética das placas de vídeo

\begin{tabular}{cccccccccccc}
\hline Metal & $\mathrm{Ag}$ & $\mathrm{Al}$ & $\mathrm{Au}$ & $\mathrm{Cu}$ & $\mathrm{Fe}$ & $\mathrm{Ni}$ & $\mathrm{Pb}$ & $\mathrm{Sn}$ & $\mathrm{Zn}$ & Outros & Total \\
\hline $\begin{array}{c}\text { Massa } \\
(\%)\end{array}$ & 0,07 & 0,9 & 0,02 & 15,2 & 0,1 & 0,1 & 1,3 & 1,9 & 1,7 & 0,1 & 21,3 \\
\hline
\end{tabular}

A Tabela 1 mostra que a fração magnética das placas de vídeo possui um total de aproximadamente $21 \%$ dos metais presentes na placa como um todo. Dado que as placas de vídeo são compostas por metais em $40 \%$, podemos dizer então que $53 \%$ destes metais se encontram na fração não magnética. Também é possível notar, a partir da comparação com dados da Tabela 1, que a maior parte de metais como a prata, alumínio, ouro, cobre e zinco ficaram na fração não magnética da placa de vídeo.

É evidente que o cobre representa a maior parte dos metais contidos nas placas de vídeo (65\%) e que $65 \%$ deste se encontra na fração não-magnética das placas. Tal componente é de importante recuperação, uma vez que é abundante nas placas e também muito utilizado industrialmente. Assim, deve-se pensar se concentrar este metal através de uma separação magnética para posterior recuperação é interessante, pois pode significar um menor consumo de energia e geração de efluentes no que diz respeito a processos hidrometalúrgicos que são usualmente aplicados. Entretanto, a perda de 35\% de material no processo de separação, o que pode não ser vantajoso, pensando nos gastos com a separação e a perda de material considerada.

No que diz respeito aos metais preciosos, como o ouro e a prata, que também possuem maior abundância na fração não magnética das placas de vídeo $(75 \%$ e $70 \%$, respectivamente), a separação magnética já não se mostra tão efetiva quanto

* Contribuição técnica ao 69 Congresso Anual da ABM - Internacional e ao 14ํㅡㄹ ENEMET - Encontro Nacional de Estudantes de Engenharia Metalúrgica, de Materiais e de Minas, 21 a 25 de julho de 2014, São Paulo, SP, Brasil. 


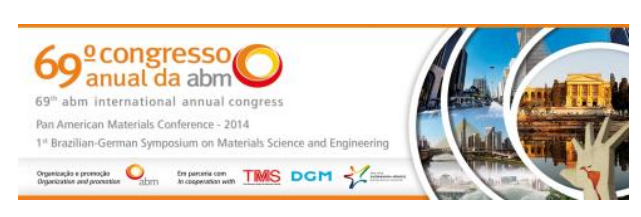

ao rendimento na recuperação destes metais, pois esta fração contém $5 \%$ em metais preciosos, enquanto a placa sem separação contém 4\%. Então, a separação magnética não seria um processo vantajoso, uma vez que haveria maior gasto de tempo e energia, além da perda de certa quantidade de material, para uma diferença de recuperação muito pequena.

\section{CONCLUSÃO}

O aumento da geração de resíduos de equipamentos eletro eletrônicos (REEE) chama a atenção por gerar problemas ao meio ambiente e também por conterem substâncias que podem ser nocivas à saúde em sua composição. Visando aumentar a eficiência no processo de recuperação dos metais, evitando a geração excessiva de efluentes e descarte desnecessário de sólidos, as placas de circuito interno proveniente de computadores em desuso foram submetidas ao processo de separação magnética e caracterizadas.

Dentre os metais presentes nas placas, aqueles que se apresentaram mais abundantes na fração não magnética desta foram: ouro, prata, alumínio, cobre e zinco. Analisando o quão vantajoso seria o processo de separação magnética, tendo em vista a representatividade desses metais na placa como um todo e apenas na fração não magnética, chegou-se a conclusão de que, para a recuperação de metais preciosos, a separação magnética seria indiferente, uma vez que representam quase a mesma fração tanto sem quanto com a separação magnética. Já o cobre se apresenta mais abundante na fração não magnética da placa de vídeo, porém a perda de $35 \%$ de material na separação, deve-se considerar se de fato seria positiva a separação, considerando por um lado os gastos de energia deste processo e, por outro, a menor geração de efluentes e resíduos sólidos referentes ao processo de recuperação deste metal propriamente dito.

\section{Agradecimentos}

Agradecemos ao Conselho Nacional de Desenvolvimento Científico e Tecnológico (CNPq) e à Fundação de Amparo à Pesquisa do Estado de São Paulo (FAPESP) pelo apoio financeiro que nos permitiu realizar os ensaios e pesquisas.

\section{REFERÊNCIAS}

1 He W, Li G, Ma X, Wang H, Huang J, Xu M, et al. WEEE recovery strategies and the WEEE treatment status in China. J Hazard Mater [Internet]. 2006 Aug 25 [cited 2014 Mar 13];136(3):502-12. Available from: http://www.ncbi.nlm.nih.gov/pubmed/16820262

2 Araújo MG, Magrini A, Mahler CF, Bilitewski B. A model for estimation of potential generation of waste electrical and electronic equipment in Brazil. Waste Manag [Internet]. 2012 Feb [cited 2014 Feb 5];32(2):335-42. Available from: http://www.ncbi.nlm.nih.gov/pubmed/22014584

3 Li J, Lopez BN, Liu L, Zhao N, Yu K, Zheng L. Regional or global WEEE recycling. Where to go? Waste Manag [Internet]. 2013 Apr [cited 2014 Mar 13];33(4):923-34. Available from: http://www.ncbi.nlm.nih.gov/pubmed/23337392

4 Turner M, Callaghan D. UK to finally implement the WEEE Directive. Comput Law Secur Rev [Internet]. 2007 Jan [cited 2014 Mar 14];23(1):73-6. Available from:

http://linkinghub.elsevier.com/retrieve/pii/S026736490600118X

\footnotetext{
* Contribuição técnica ao $69^{\circ}$ Congresso Anual da ABM - Internacional e ao 14ํㅡㄹ ENEMET - Encontro Nacional de Estudantes de Engenharia Metalúrgica, de Materiais e de Minas, 21 a 25 de julho de 2014, São Paulo, SP, Brasil.
} 
5 Hall WJ, Williams PT. Separation and recovery of materials from scrap printed circuit boards. Resour Conserv Recycl [Internet]. 2007 Sep [cited 2014 Feb 3];51(3):691-709. Available from: http://linkinghub.elsevier.com/retrieve/pii/S0921344906002643

6 Mazon MT, Azevedo AMM, Pereira NM, Silveira MA. (2012). Does environmental regulation foster the diffusion of collaborative innovations? A study on electronics waste regulation on Brazil. Procedia - Social and Behavioral Sciences, pp. 259 - 268.

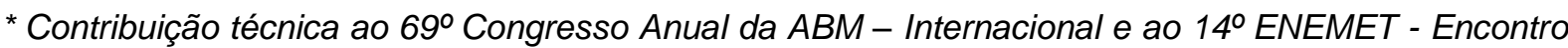
Nacional de Estudantes de Engenharia Metalúrgica, de Materiais e de Minas, 21 a 25 de julho de 2014, São Paulo, SP, Brasil. 